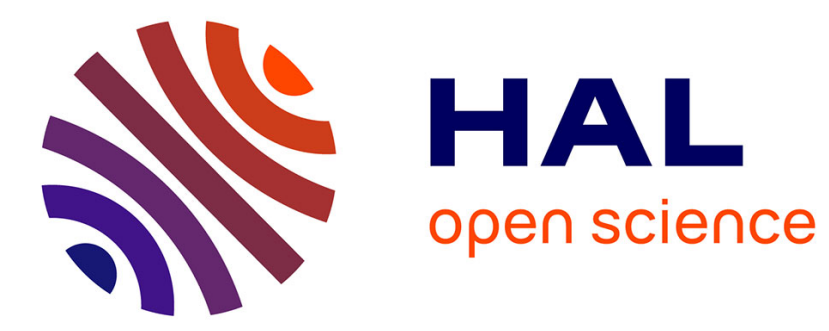

\title{
Modelling a regional reorganization of cardiovascular surgery provision
}

Anne Quesnel-Barbet, Marie Christine Nuttens, Bruno Aublet-Cuvellier, Henri Warembourg, Alain Prat, Pierre Jean Thumerelle, Régis Beuscart

\section{- To cite this version:}

Anne Quesnel-Barbet, Marie Christine Nuttens, Bruno Aublet-Cuvellier, Henri Warembourg, Alain Prat, et al.. Modelling a regional reorganization of cardiovascular surgery provision. Health and Place, 2005. hal-02006804

\section{HAL Id: hal-02006804 https://hal.science/hal-02006804}

Submitted on 4 Feb 2019

HAL is a multi-disciplinary open access archive for the deposit and dissemination of scientific research documents, whether they are published or not. The documents may come from teaching and research institutions in France or abroad, or from public or private research centers.
L'archive ouverte pluridisciplinaire HAL, est destinée au dépôt et à la diffusion de documents scientifiques de niveau recherche, publiés ou non, émanant des établissements d'enseignement et de recherche français ou étrangers, des laboratoires publics ou privés. 


\section{Modelling a regional reorganization of cardiovascular surgery provision}

Anne QUESNEL-BARBET ${ }^{1,2,3}$, Marie Christine NUTTENS ${ }^{1}$, Bruno AubletCuvellier ${ }^{2}$, Henri WAREMBOURG ${ }^{4}$, Alain PRAT ${ }^{4}$, Pierre Jean THUMERELLE ${ }^{3}$, Régis BEUSCART ${ }^{1,2}$

1-Centre d'Étude et de Recherche en Informatique Médicale (CERIM), Faculté de Médecine, 1, Place de Verdun, F-59045 Lille cedex, France.

2-Département d'Information Médicale (DIM), Centre Hospitalier Régional et Universitaire (CHRU), Administration générale, 2 avenue Oscar Lambret, F-59037 Lille cedex, France.

3-Laboratoire de Géographie Humaine, UPRESA-EA 1036, Université des Sciences et Technologies de Lille (USTL), F-59655 Villeneuve d'Ascq cedex, France.

4-Clinique de chirurgie cardiovasculaire, Centre Hospitalier Régional et Universitaire (CHRU), Hôpital Cardiologique, Boulevard du Pr Jules Leclercq, F-59037 Lille cedex, France.

Correspondence: Anne QUESNEL-BARBET*, CERIM, Faculté de Médecine, 1, Place de Verdun, F-59045 Lille Cedex, France.

Phone number: +33320626826

Fax number: +33320521022

E-mail: aquesnel@univ-lille2.fr 


\begin{abstract}
The Nord - Pas-de-Calais region of France is under-served in terms of access to cardiovascular surgery services, as illustrated by relatively high levels of waiting list mortality. This prompted the decision to create a new surgical unit (notably with facilities for extracorporeal circulatory support) in the region's densely populated, former industrial heartland called the "Mining Basin". Geographical and epidemiological modelling was used prospectively to estimate the likely future level of activity of the existing public sector cardiovascular surgery units. Furthermore, information on the regional population distribution and the likely pattern of service use enabled us to estimate the new unit's potential activity. Our simulations produced nine scenarios which describe variations in the existing public units' activity ranging from $-54 \%$ to $+95 \%$. This type of approach should enable policy makers to improve the organization of healthcare provision.
\end{abstract}

\title{
KEYWORDS
}

cardiovascular surgery; geographical and epidemiological methods; spatial modelling; accessibility; PMSI database; regional health planning. 


\section{INTRODUCTION}

The heterogeneous distribution of healthcare provision has been described in both developing and developed countries as varied as South Africa, the UK, the USA and France, and is seen to depend on a range of geographical (distance), quantitative (number of hospitals per inhabitant) and qualitative factors (market-led ideology, hitech medical equipment, varying levels of health care provision) (Picheral, 1990; Gatrell, 2002). Indeed, differences in access to healthcare (Tanaka et al., 1981) produce inequalities in terms of health.

France's Nord - Pas-de-Calais region provides an example of deficient healthcare planning, as notably illustrated by the poor provision of hi-tech disciplines, where the region lags behind in comparison to other French regions. Health policy managers in the region were particularly criticized about the under-provision of healthcare facilities in the field of cardiovascular surgery, which was highlighted by a relatively high pre-operative mortality rate at Lille University Hospital.

In their efforts to respond to the region's healthcare priorities and to adhere to a French national healthcare organization policy that seeks to minimize costs by improving hospital organization (De Pouvourville, 1998) and promoting healthcare networks, both health professionals and health policy makers decided to give the region an additional (fourth) cardiovascular surgical unit with an innovative administrative status, situated at Lens Hospital.

Our aim during the planning period preceding the unit's opening was to answer questions such as how the creation of a new cardiovascular surgery care unit would influence demand, and what the consequences for existing cardiovascular surgery units would be. We therefore decided to use modelling to predict positive and negative 
impacts on catchment areas and on inpatient recruitments for Lille University Hospital's current cardiovascular surgical services.

\section{BACKGROUND}

An unpublished local study (performed in 1993 on the basis of a retrospective registry) had found that $\mathbf{2 \%}$ of inpatients on the local waiting list had died before the scheduled date for surgery. Until recently, there were three cardiovascular surgery units in the Nord - Pas-de-Calais region: two in the Lille University Hospital (units 1 and 2) and one (unit 3) in a private clinic (the "Clinique du Bois") situated within the Lille metropolitan area.

\section{Economic and geographical reference data}

Nord - Pas-de-Calais is France's northernmost region and is home to almost four million inhabitants: it is a former industrial heartland characterized by a "mining basin" (running across the central part of the region) and the three traditional pillars of its economy: coal, metallurgy and textiles. Since the 1960s, a persistent economic crisis has resulted in a high unemployment rate $(14.6 \%$ of the workforce in 1999 , compared to a national average of $10.6 \%$ ) and deteriorating housing conditions (INSEE, 2000). On the whole, France shows a nationwide North-South economic and social gradient, with the North being relatively disadvantaged (Chambaz and Legris, 1997).

\section{Cardiovascular epidemiology in Nord - Pas-de-Calais}

In the early 1980s, the regional capital (Lille) was one of three French survey centres (located within areas of about one million inhabitants in the North, South and East of the country respectively) selected to participate in the Multinational Monitoring of Trends and Determinants in Cardiovascular Disease (MONICA) project coordinated 
by the World Health Organization (WHO). The project's goal was to set up ischaemic heart disease registries: the resulting epidemiological data revealed a North-South geographic gradient in terms of observed mortality, which was found to be much more pronounced for case fatality than for incidence (Amouyel et al., 2000b; Lang et al., 1999).

For the two years 1997-1998, mortality rates among hospital patients with heart disease were $23.6 \%$ for men and $32.7 \%$ for women in the 35 to 74 years age band (Amouyel et al., 2000a) - the highest of the three French MONICA registries. In Lille, about two thirds $(65 \%)$ of inpatients with suspected heart attack $(1,249$ men and 258 women in all) were admitted to a healthcare establishment - the remainder went without treatment or merely received ambulatory care. This figure is low in comparison to the other French centres in Strasbourg (68\%) and Toulouse (71\%).

For the Nord - Pas-de-Calais population over the period 1988-90, the overall Standardized Mortality Ratio (SMR) for myocardial infarction diseases was 126.0, and did not differ greatly between men and women. This was the second highest rate in France, compared to the other 21 mainland regions (Table 1) (CID, 1993) (FNORS, 2001; Salomez et al., 1995).

\section{Healthcare supply and demand}

In light of these regional epidemiological observations, one would expect the supply of cardiology services to match the epidemiological situation. In fact, this is not the case: the Nord - Pas-de-Calais region's deficit in healthcare provision is particularly significant in cardiology, where the extracorporeal circulation surgical intervention rate (hereafter referred to as "extracorporeal circulation rate") is 4.53 per 10,000 population, compared to a national average of 5.96 (Baubeau et al., 1994; Mino et al., 1997). The French national healthcare authorities have defined the theoretical optimal density of 
cardiovascular surgical units as one per 850,000 inhabitants, based on the nationwide average. Such a density would correspond to 4.66 cardiovascular surgical units in Nord - Pas-de-Calais, whereas in fact only three exist currently. Hence, the region's healthcare planning authorities decided to create a new unit in Lens - a city located in an area of the mining basin with the region's highest population density.

By using population census information and data on the level of morbidity and existing patterns of service use, we were able to provide estimates of the new unit's future activity. These estimates were used prospectively to evaluate planning options.

\section{MATERIALS AND METHODS}

The methodology adopted for our geographical modelling first required us to estimate the cardiovascular surgery activity in Nord - Pas-de-Calais throughout the year of 1996 , designated as the study year. The activity pattern only concerned admissions to the Lille University Hospital - the sole regional establishment for which adequate details were available. Data were extracted from the French national PMSI database ("Programme de Médicalisation des Systèmes d'Information", a French hospital information database adapted from the Diagnosis Related Group (DRG) classification) in order to determine patterns of service use in Lille University Hospital's two cardiovascular surgical units (comprising 56 and 28 beds respectively).

\section{Activity data}

The PMSI is derived from Fetter's Diagnosis Related Group (DRG) system, initially described and used in the United States (Fetter et al., 1985; Smits et al., 1984) (Fetter et al., 1985; McMahon et al., 1988; Smits et al., 1984; Vergnenegre et al., 1999; Ganry et al., 1999). The system's aim is to define the budget allocation basis for each public hospital according to a set of basic information on each hospital stay (Bensadoun, 
2001; Vergnenegre et al., 1999; Borella et al., 2000; Lukacs et al., 1996): since 1995, every healthcare establishment in France has been obliged to record certain data (age, sex, residential post code, diagnosis and principal medical acts) for each inpatient stay. Diagnoses are coded according to the WHO international classification of diseases. These data are transmitted to healthcare authorities so that a budget allocation basis can be derived from the DRG assigned to each stay. Although mainly used for economic purposes, the database contains useful information for healthcare planning activities (Quantin et al., 1999).

Since the PMSI is only mandatory for public sector structures, detailed data were only available for the two public units of cardiovascular surgery units. The overall level of activity was the sole available information for the private unit (also located in Lille).

In order to describe activity, the cardiovascular surgery units defined thirteen disease groups based on PMSI diagnosis segmentation. These groups were aggregated into five classes, only one of which concerned open heart surgery, i.e. the two subgroups (coronary disease and valvular disease) usually requiring extracorporeal circulatory support.

\section{Mapping healthcare areas}

In France, regional healthcare authorities determine sanitary sectors for planning purposes based on population density and the location of facilities (DRASS, 1994), mainly via analysis of public and private hospital catchment areas. This definition is part of the Regional Sanitary Organization Schema (SROS) which defines healthcare policy in each French region.

In Nord - Pas-de-Calais, eleven sanitary sectors are defined, each being served by a town with major healthcare facilities. The sectors each contain about 200,000 inhabitants, except for that including Lille, which accounts for more than one million 
inhabitants. The mining basin mainly covers the central districts represented by Béthune (4), Lens (5), Douai (6) and a part of the eastern district of Valenciennes (7) (Figure 1).

We defined a table for translation of the 400 residential post codes used in the PMSI system into the eleven sanitary sectors modelled in our simulation process.

\section{Epidemiological hypotheses}

To forecast the future numbers of cardiovascular surgical acts (referred to hereafter as "estimated numbers"), we used two epidemiological hypotheses:

1: we assumed that morbidity requiring hospitalisation was homogeneously distributed across the entire region. This choice is justified by the national healthcare planners' criterion that defines a fixed, nationwide target of 1 cardiovascular surgery unit per 850,000 inhabitants, without further taking into account epidemiological and demographic indices (age, sex, etc.).

2: the current overall surgical intervention rates cannot correspond to a good estimation of the region's true cardiovascular surgery needs, since the significant death rate for patients on the waiting list indicates a lack of access to care.

\section{Calculation of estimated surgical intervention rates in Nord -}

\section{Pas-de-Calais}

To avoid underestimation problems, the estimated surgical intervention rate was computed for each district (i.e. on the sanitary sector level) separately from the observed extracorporeal circulation (ECC) surgical intervention rates for each of the region's public sector units. For both disease sub-groups (valvular disease and coronary disease), the highest district rate was retained as a credible measure of the whole region's true needs. 
For the simulation process, we considered that the potential, regional, surgical intervention rates with extracorporeal circulatory support were equivalent to the mean and maximum literature values observed in the French regions as a whole (Mino et al., 1997). The expected numbers of cases were derived by applying each of these rate parameters to the Nord - Pas-de-Calais region's population.

\section{Calculation of the new unit's estimated activity}

Estimates of the new unit's activity were derived by combining the population numbers in the likely catchment area with differing estimates of the true level of demand. The potential catchment area of the new cardiovascular surgery unit in Lens is mainly defined within three districts (Lens, Béthune and Douai). Three hypotheses were made to estimate future activity: firstly, as explained above, the highest observed district surgical intervention rates of extracorporeal circulation within Nord - Pas-de-Calais were applied to the relevant local population. The second and the third numbers of expected cases were respectively derived from the mean and maximum surgical intervention rates reported in the country as a whole.

At the time of this study, national extracorporeal circulation surgical intervention rates broken down by age and sex were not available. Hence, the results of the simulation could not be normalised with respect to these factors. The Nord - Pas-deCalais's age structure is known to be skewed towards younger age bands than the national average. As shown in Table 2, the population aged between 60 and 79 (which forms the main age band in terms of extracorporeal circulation surgery) represents $15.8 \%$ of the region's total population versus $17.2 \%$ in France nationally. The sex ratio in the region is quite similar to the national figure. These demographic characteristics would suggest that regional needs in Nord - Pas-de-Calais are lower than in France generally but this factor is unlikely to completely offset the structural, epidemiological 
effects illustrated by a high standardised mortality ratio (126.0) for myocardial infarction, for instance.

\section{Computation}

The combination of estimations from the three overall regional estimates with the three estimations of extracorporeal circulation cases at the new unit leads to nine different activity scenarios. It was assumed that the extracorporeal circulation activity of the private unit in Lille will remain constant at its current level of 530 surgical operations per year. Since the new unit's activity is fixed in each situation (405, 542 and 722 ECC), the only varying item is the Lille University Hospital unit's predicted activity, with 9 scenario outcomes. The outcomes are expressed as the difference between the estimated future number of extracorporeal circulation operations and the current number carried out.

\section{Simulation of extra-regional attraction and leakage}

Since an administrative region is not a closed system with impenetrable boundaries, we estimated the patient flow out of and into the region. The patient inflow was directly measured from the available data for the public unit because a patient's residential post code is always mentioned in the PMSI records. This probably underestimates the inflow, since residential data for the private unit's inpatients were not made available to us. The extra-regional patient loss was estimated from the leakage rate measured in a national study (Mino et al., 1997).

\section{RESULTS}

During the study year, a total of 1,676 operations with extracorporeal circulatory support were performed in the Nord -Pas-de Calais region: 1,146 in the public Lille 
University Hospital and 530 in the private unit also located in Lille, the region capital. Details of the numbers of cases of surgery in each unit are given in Table 3.

\section{Overall regional needs}

The observed number of cases and extracorporeal circulation surgical intervention rates for each district are listed in Table 4. The observed surgical intervention rates in the sanitary sectors range from 0.95 to 2.65 cases per 10,000 inhabitants for coronary disease and between 0.84 and 1.83 for valvular disease. We retained the highest rates as an estimate of local needs, i.e. 2.65 [2.16-3.22] and 1.83 [1.35-2.41] respectively. This leads to a regional estimated number of 1,051 inpatients per annum for coronary disease, 725 inpatients for valvular disease and thus a total of 1,776 operations. On the basis of our assumptions, these outcomes give an overall estimation of the need for extracorporeal circulation surgery of 4.48 operations per 10,000 inhabitants.

The mean national extracorporeal circulation surgical intervention rate is recorded as being 6.0 cases per 10,000 inhabitants. Applying this figure to the Nord Pas-de-Calais regional population estimates the need at about 2,379 operations per year. The Aquitaine region had the highest surgical intervention rate in France in 1994, at 8.0 cases per 10,000 inhabitants. Again, if this rate were applied to Nord - Pas-de-Calais, 3,172 patients would need this kind of surgery.

\section{The new unit's forecast activity}

Similar calculations applied to the new unit's potential catchment area are summarized in Table 5: the results range from 405 to 722 operations per year. The national average number of extracorporeal circulation operations per surgeon is known 
to be 146 operations per year. Therefore, the new unit's activity would correspond to the work of between three and five surgeons.

\section{Simulation summary}

Table 5 summarizes nine scenarios. The outcomes are expressed as the variation in the predicted activity of the two Lille University Hospital units. This factor ranges from -622 to $+1,091$ operations with extracorporeal circulatory support, depending on the rates applied to the regional population and the new unit's operating capacity. The mean national extracorporeal circulation rate leads to a midway situation which increases the university hospital's activity by 161 operations.

\section{Attraction and leakage}

In 1996, twenty-three inpatients requiring extracorporeal circulatory support were treated in the public units, even though they lived outside the region and were not therefore included in the surgical intervention rate computations. This corresponds to the extra-regional inflow of Lille University Hospital's two units. However, the results of the national survey showed that 89 inpatients living in Nord - Pas-de-Calais were hospitalized outside the region (5.0\%). Increasing the regional cardiovascular surgery capacity could therefore result in reduced patient outflow and thus produce an overall increase in regional activity corresponding to 112 additional patients.

\section{DISCUSSION}

This work shows the potential impacts of the creation of a new, regional, cardiovascular surgical unit on the overall activity of the existing public units at Lille University Hospital. Depending on the simulation parameters, extracorporeal circulation surgery may increase by as much as 95 percent or decrease by as much as 54 percent. 


\section{Rate hypotheses}

As is often the case, the critical issue is one of estimating the real need for care. By using the highest rates for valvular disease and coronary disease estimated separately, we can approximate the population's real needs at the sanitary sector level. In fact, current levels of activity do not represent the true overall need, since the waiting list indicates a significant mortality rate prior to the scheduled surgery date. The extracorporeal circulation rate computed in this way is lower than the French national rate, while the regional, standardised mortality ratio for myocardial infarction is the second highest of the 21 French regions (Table 1). Thus, one can legitimately use the mean and highest extracorporeal circulation rates as potential estimates of the region's true needs. The new unit's activity must also be estimated according to different scenarios. Even when applying a hypothesis of spatial homogeneity, Figure 1 shows that the highest rates for surgery with extracorporeal circulatory support are located in the neighbourhood of Lens. Another point is the difficulty of prospectively estimating the new unit's real catchment area: in France, a patient can freely choose the hospital where he or she wishes to be treated. However, this "freedom of choice" decreases in emergency situations and for hi-tech treatment. While distance is known to be the main determinant of a hospital's catchment area (Mizrahi and Mizrahi, 1992-93; Mizrahi et al., 1963), another important component is the reputation of the surgical staff, which is quite difficult to predict.

\section{Consequences of the new organizational scheme}

The creation of this expensive, new, hi-tech unit should result in a number of advantages for the various healthcare stakeholders (i.e. patients, surgical healthcare professionals and health policy makers). 
With better distribution of units across the region's territory, several patient benefits are expected:

*improved healthcare access and quality.

*an increase in the overall quality of care for cardiovascular conditions.

*reduced access time to services.

*hospitalisation at the nearest site, thus facilitating social and family aspects of care.

Health professionals involved in cardiac surgery expect that creation of the new unit will lead to a more balanced workload in the region's surgical units as a whole, resulting in:

*better chances of effective recovery from disease.

*a significant reduction in waiting list mortality.

*an increase in the diagnosis rate for cardiovascular diseases.

This creation is also an opportunity to create a healthcare network which promotes cooperation between cardiovascular staff. The existence of the network is a critical point for the efficiency of the new healthcare organisation, especially for emergency management.

Healthcare policy makers are also in favour of the new organizational scheme for healthcare provision. Regionalization is a regulatory approach to rationalising resource allocation, particularly in the case of highly specialized medical technologies.

The "regionalization" phenomenon should produce good expected outcomes in terms of decreased surgical mortality rates, even if the travelling distance to hospital increases. For healthcare planners and researchers, the new unit's creation will have positive effects on accessibility within our region, where facility distribution is 
acknowledged to be insufficient. The main objective of recent reforms in the French healthcare system is to maximize accessibility by optimizing spatial distribution of healthcare facilities. By locating the new unit in a high density demographic area, the improvement of regional accessibility could contribute to the abolition of waiting list mortality.

\section{Accessibility}

Striking a balance between accessibility and quality of care is difficult. On one hand, accessibility tends to increase the number of healthcare facilities and to decrease the mean distance between a given healthcare facility and its patients. On the other hand, quality of care follows a volume-outcome relation (meaning that a minimum volume of activity is required to ensure a good standard of care), and thus tends to reduce the number of units (Ruey-Kang R. Chang and Thomas S. Klitzner, 2002) (NHS and NIHUL, 1996).

Distance decay is a spatial phenomenon which means that as a service or facility becomes more distant, fewer people will patronize it. Distance decay rates operate differently in different social groups (Gregory et al., 2000) (Thouez et al., 1988) (Phillips, 1995, p, 210).

In France, certain authors have cited "a long geographic distance" as a limiting factor for patients seeking access to healthcare (Mizrahi and Mizrahi, 1992-93; Mizrahi et al., 1963): this is a main determinant of people's individual decisions (the "social distance") to travel from their place of residence to the healthcare facility, except in an emergency context. Patient age may also have an impact on access to care, since elderly patients are less access-advantaged in such a case (Fleming et al., 1991).

For instance, it has been shown that whereas in-hospital mortality may not be associated with distance from services, shorter distance to services and better 
availability of services within a relatively small geographic area are strongly related to increased utilisation (Gregory et al., 2000).

The location of the new unit in the centre of the mining basin is therefore relevant, since the latter is characterized by its low socio-economic level - a factor also known to increase the risk of coronary heart disease (Sundquist et al., 2000).

The problem with regard to these sociopolitical opinions or views is emphasized by a schema from (Phillips, 1995, p, 191-219) and (Vigneron, 2001, p, 18) showing the need for a balance between accessibility and quality, and is directly related to the population's socio-economic characteristics. The perception of quality can depend on the socio-economic and psychological context, and is perceived differently in rural and urban areas (Phillips, 1995).

Thus, the perception of accessibility and quality of care is of major interest in a former industrial heartland, whose residents typically belong to lower social class and are probably more in favour of proximity and of shorter distances to the local hospital (rather than a long trip to the University Hospital). These aspects of perceived quality could contribute to psychological gains or losses in terms of the French population's positive perception of its healthcare system.

Other approaches have been used to study the impact of changes in facility configuration. Gravity models based on Reilly's work (Reilly, 1959) or more recently on Wilson's entropic model (Wilson, 1971) have been used for this purpose. However, their main utilisation to date has been in resource allocation for existing facilities (Mayhew and Leonardi, 1982). Predicting the impact of a new structure using the gravity model requires estimation of its "mass", which is quite difficult. Although a hospital's caseload is usually employed as the prime parameter of mass, the impact of the reputation of a unit and its medical staff may strongly influence the mass especially in France, where the choice of a hospital or clinic is not driven by health 
insurance considerations. Furthermore, factors such as competition between private and public structures could also impact on the mass of a new unit. Thus, although such models may accurately describe the use of hospitals at a given time, they may be inaccurate in predicting utilisation patterns after changes in the number and location of hospitals (McLafferty, 1988): this is why we chose to use a population-based model for our simulations.

It will be interesting to study the impact of the new organizational scheme on the attraction and leakage rates for the region as a whole. Once the new unit has been created and once its activity has stabilized, it will be very interesting to compare the real catchment area and surgical intervention rates to the hypothesis and scenarios used in our model based on PMSI data. However, the most essential goal of future work will be to monitor the region's cardiovascular epidemiological indicators and to assess the unit's overall effect on the population's health.

\section{Database limitations}

Use of the PMSI data base for planning purposes is novel, since it is the first time in our region's history that these data have been exploited as an geoepidemiological tool. (Quesnel et al., 1998). This kind of use should grow, since a number of scientific groups are interested in working with geocoded healthcare data (Rodrigues, 1999; Borella et al., 2000; Laurent, 2002). Furthermore, there are plans to provide anonymous record linkage, which would enable one to link personal records from different hospital files. This procedure complies with the European legislation on privacy and data protection (Quantin et al., 2000; Kerkri et al., 1999) and will improve the feasibility and the relevance of epidemiological and geographical research analyses. However, since the PMSI system was designed for budget allocation purposes, it does 
not include socio-economic variables, thus limiting the scope of epidemiological studies based on these data.

Nevertheless, the real quality of the PMSI data is not yet precisely known. As the main operational use of the data is to compute the hospital budget (with penalties levied on establishments providing incomplete and poor data quality), more attention is now being focused on data quality and the overall standard is set to rise in hospitals where the information is daily collected. In our study, this possible lack of quality strengthens our hypothesis that current needs are underestimated.

This approach can also be generalised: our methods can benefit other regions and populations within the framework of various hospital planning projects, since diagnostic or surgical acts can both be used to estimate the current activities of medical and surgical units. The main problem is one of data inaccessibility: the governmental healthcare policy makers managing the database at the regional and national levels are very careful about its use. Furthermore, the CNIL ("Commission Nationale de l'Informatique et des Libertés", the French National Commission for Data Protection) (SESI, 1997) restricts the use of the PMSI database at detailed spatial scales (the commune, the district within a town etc.) for privacy reasons (Picheral, 1990). One is not allowed to analyse disease data at a territorial level, which in some cases can make patient identification possible.

\section{CONCLUSION}

By evaluating indicators such as waiting list mortality, waiting time, extraregional patient leakage and the number of surgical operations requiring extracorporeal circulatory support, we have been able assist policy makers and other healthcare professionals with the regional planning of healthcare services and the adjustment of facilities to match patient needs. 
Better data quality and more precise monitoring of regional cardiovascular surgical activity after the opening of the new unit will be useful in helping decision makers to adapt healthcare supply to demand and in ensuring that all of our region's cardiovascular surgical units work together in a complementary manner. 


\section{REFERENCES}

Amouyel, P., Ferrieres, J., Arveiler, D., Ducimetiere, P., Bingham, A., Montaye, M., Beauchant, S., Cottel, D., Graux, C., Lemaire, B., Marecaux, N., Steclebout, C., Ruidavets, J.B., Deckers, D., Saulet, C., Barrere, S., Haas, B., Lamamy, N., Pierau, F., Wagner, A., Schaffer, P., 2000a. L'infarctus du myocarde en France, incidence, létalité hospitalière, lieux de prise en charge. In: Fédération Francaise de cardiologie reconnue d'utilité publique (Eds.), Les registres français des cardiopathies ischémiques 1997-1998. Paris, pp. 11.

Amouyel, P., Montaye, M., Bauters, C., 2000b. Epidémiologie de la maladie coronaire et hémodynamique coronaire. http://www.pasteurlille.fr/france/recherche/u508.htm.

Baubeau, D., Mino, J.C., Bourgueil, Y., Baubeau, D., Chaillet, M.P., Cong, W.H., Hofmann, G., Ruelle, S., Vibet, M.N. (Report), 1994. Activité des unités de chirurgie cardiaque françaises en 1994. La Direction des Hôpitaux (D.R.H.) Caisse Nationale d'Assurance Maladie (C.N.A.M) - l'Ecole Nationale de Santé Publique (E.N.S.P.), Paris.

Bensadoun, H., 2001. The Medical Information Systems Project clinical coding and surgeons: why should surgeons code and how? J Chir (Paris) 138 (1), 6-14.

Borella, L., Peuvrel, P., Sauvage, M., Maraninchi, D., Philip, T., 2000. A study based on national DRG data to evaluate work load and practice relating to cancer patients in not-for-profit hospitals. Rev Epidemiol Sante Publique 48 (1), 53-70.

Chambaz, C., Legris, B., 1997. La géographie du niveau de vie : évolutions récentes. http://www.insee.fr/fr/ppp/publications/list_paru.asp?coll=1\&typ=doc\&avis=1.

CID, 1993. CID 1993 Chiffres et indicateurs départementaux, Tome 1: La métropole. (ENSP) Ecole Nationale de Santé Publique, Rennes. 
De Pouvourville, G., 1998. Comment prendre en compte les effets structurants des équipements hospitaliers publics ? Une approche économique. Santé et économie. Les-Cahiers-Du-Gratice (15), 79-89.

DRASS (Report), 1994. Nord - Pas-de-Calais - Shéma Régional d'Organisation Sanitaire - October 1994.

Fetter, R.B., Freeman, J.L., Mullin, R.L., 1985. DRGs: how they evolved and are changing the way hospitals are managed. Pathologist 39 (6), 17-21.

Fleming, C., D'Agostino, R.B., Selker, H.P., 1991. Is coronary-care-unit admission restricted for elderly patients? A multicenter study. American Journal of Public Health 81 (9), 1121-6.

FNORS, 2001. La santé observée dans les régions de France : Synthèse nationale des tablaux de bord régionaux sur la santé. Féderation nationale des observatoires régionaux de la santé, Paris.

Ganry, O., Bonhomme, C., Kadi, D., Dubreuil, A., 1999. Analysis of the variation of length of stay in a homogeneous group of diabetic patients. Ann Endocrinol (Paris) $60(5), 408-413$.

Gatrell, A.C., 2002. Geographies of Health : an introduction. Blackwell Publishing Ltd, Oxford.

Gregory, P.M., Malka, E.S., Kostis, J.B., Wilson, A.C., Arora, J.K., Rhoads, G.G., 2000. Impact of geographic proximity to cardiac revascularization services on service utilization. Medical Care 38 (1), 45-57.

INSEE, 2000. Taux de chômage en données corrigées des variations saisonnières, Région Nord - Pas-de-Calais. http://www.insee.fr/fr/insee regions/nord-pas-decalais/rfc/docs/01-03.pdf

http://www.insee.fr/fr/insee regions/picardie/Rfc/docs/ipp71-01.pdf. 
Kerkri, E., Quantin, C., Yetongnon, K., Allaert, F.A., Dusserre, L., 1999. Application of the medical data warehousing architecture EPIDWARE to epidemiological followup : data extraction and transformation. Stud Health Technol Inform 68 414-418.

Lang, T., Ducimetiere, P., Arveiler, D., Amouyel, P., Ferrieres, J., Ruidavets, J.B., Montaye, M., Haas, B., Bingham, A., 1999. Trends and geographical disparities in coronary heart disease in France: are results concordant when different definitions of events are used? International Journal Of Epidemiology 28 (6), 1050-1058.

Laurent, J.F., 2002. Update in medical informatics in oncology. Bull Cancer 89 (1), 139-245.

Lukacs, B., Cortesse, A., Hermieu, J.F., Desgrandchamps, F., Conort, P., Desportes, L., Hoznek, A., Leprise, P., 1996. Problems raised by representation of activities in urology. Cooperative study by the urology services of the AP - HP (Public Services - Paris Hospitals). Prog Urol 6 (3), 415-423.

Mayhew, L.D., Leonardi, G., 1982. Equity, efficiency, and accessibility in urban and regional health-care systems. Environment and Planning A 14 1479-1507.

McLafferty, S., 1988. Predicting the effect of hospital closure on hospital utilization patterns. Soc Sci Med 27 (3), 255-62.

McMahon, L.F.J.r., Shapiro, L.R., Weissfeld, L.A., Billi, J.E., 1988. Prior hospitalization experience of DRG outliers versus inliers. Med Care 26 (4), 423429.

Mino, J.C., Bourgueil, Y., Baubeau, D., Chaillet, M.P., Cong, W.H., Hofmann, G., Ruelle, S., Vibet, M.N., 1997. Cardiac surgery in France (supply, service and needs response) : a national survey. Sante Publique 9 (4), 447-461.

Mizrahi, A., Mizrahi, A., 1992-93. Les champs d'action des équipements médicaux: distances et consommations médicales. Espace, Populations, Sociétés 333-343. 
Mizrahi, A., Mizrahi, A., Rosch, G., 1963. Les champs d'action des équipements hospitaliers. CREDOC 61-106.

NHS, NIHUL, 1996. Hospital volume and healthcare outcomes, costs and patient access. Effective Health Care 2 (8), 1-16.

Phillips, D.R., 1995. Using health services, Modelling the use of health services. In: Phillips, D.R. (Eds.), Health and Health Care in the Third World. Longman Scientific and Technical (LST) and John Wiley and Sons, Harlaw (UK), pp. 178223.

Picheral, H., 1990. Geographical scale for analysis of health care provision. Cahiers de Sociologie et de Demographie Medicales 30 (2), 155-176.

Quantin, C., Allaert, F.A., Bouzelat, H., Rodrigues, J.S., Trombertpaviot, B., BrunetLecomte, P., Gremy, F., Dusserre, L., 2000. Security of healthcare data networks used for epidemiological studies. Rev Epidemiol Sante Publique 48 (1), 89-99.

Quantin, C., Entezam, F., Brunet-Lecomte, P., Lepage, E., Guy, H., Dusserre, L., 1999. High cost factors for leukaemia and lymphoma patients: a new analysis of costs within these diagnosis related groups. J Epidemiol Community Health 53 (1), 2431.

Quesnel, A., Quesnel, B., Picheral, H., Beuscart, R., 1998. Town and country planning with a medical information system. IXème congrès mondial en informatique médicale, Proceeding of Medinfo'98, Seoul, Corée.

Reilly, W.J., 1959. Methods for the study of retail relationships. University of Texas, Austin.

Rodrigues, J.M., 1999. DRGs and inequities among French hospitals: from a new dilemma to another health care policy. Australian Health Review 22 (2), 39-52. 
Ruey-Kang R. Chang, Thomas S. Klitzner, 2002. Can regionalization decrease the number of deaths for children who undergo cardiac surgery? A theoretical analysis. Pediactrics 109 (2), 173-181.

Salomez, J.L., Lacoste, O., Spinosi, L., Cappelaere, P., Demaille, A., Fihey, D., Declercq, C., Lahoutte, C., Plancke, L., Gower-Rousseau, C., Furon, D., Alao, O., Tillard, B., Romon-Rousseau, M., 1995. La santé d'une région : État et tendances dans le Nord - Pas-de-Calais. ORS, Lille.

SESI (Report), 1997. Constitution de codes géographiques de zones de plus de 1000 habitants à partir des codes postaux. Ministère du travail et des affaires sociales République Française, Paris.

Smits, H.L., Fetter, R.B., McMahon, L.F., Jr., 1984. Variation in resource use within diagnosis-related groups: the severity issue. Health Care Financ Rev 71-78.

Sundquist, K., Lindstrom, M., Malmstrom, M., Johansson, S.-E., Sundquist, J., 2000. Social participation and coronary heart disease : a follow-up study of 6900 women and men in Sweden. Soc Sci Med In press.

Tanaka, T., Ryu, S., Nishigaki, M., Hashimoto, M., 1981. Methodological approaches on medical care planning from the viewpoint of geographical allocation model: a case study on south Tama district. Social Science \& Medicine 15 D 83-91.

Thouez, J.P., Bodson, P., Joseph, A.E., 1988. Some methods for measuring the geographic accessibility of medical services in rural regions. Med Care 26 (1), 3444.

Vergnenegre, A., Druet-Cabanac, M., Rymer, R., 1999. Interventional radiology and the medical applications of information systems: what consequences for the radiology department? J Radiol 80 (6), 565-568.

Vigneron, E., 2001. Distance et santé, la question de la proximité des soins. PUF, Paris. 
Wilson, A.G., 1971. A family of spatial interaction problems and associated developments. Environment and Planning 3 1-32. 
Table 1: Number of cardiovascular surgery units and myocardial infarction Standardized Mortality Ratios in the French regions.

\begin{tabular}{|c|c|c|c|c|c|c|}
\hline AXIS & REGIONS & $\mathrm{ON}^{\mathrm{a}}$ & $\mathrm{EN}^{\mathrm{b}}$ & $\mathrm{SMR}^{\mathrm{c}}$ & $\begin{array}{c}\% \text { pop } \\
>60 \text { years } \\
\text { old }\end{array}$ & $\begin{array}{c}\mathrm{ECC}^{\mathrm{d}} \\
\text { rates/ } 10,000\end{array}$ \\
\hline & ÎLE-DE-FRANCE & 16 & 13.00 & 93.0 & 15.8 & 5.644 \\
\hline & CHAMPAGNE-ARDENNE & 1 & 1.62 & 106.5 & 19 & 4.677 \\
\hline & PICARDIE & 1 & 2.18 & 114.5 & 17.7 & 4.677 \\
\hline & HAUTE-NORMANDIE & 1 & 2.10 & 109.5 & 17.8 & 4.787 \\
\hline $\mathrm{N}$ & CENTRE & 2 & 2.82 & 97.5 & 21.8 & 6.30 \\
\hline $\mathrm{O}$ & BASSE-NORMANDIE & 2 & 1.67 & 118.5 & 20.5 & 7.055 \\
\hline $\mathrm{R}$ & BOURGOGNE & 1 & 1.91 & 103.5 & 23.1 & 5.311 \\
\hline $\mathrm{T}$ & NORD - PAS-DE-CALAIS & 3 & 4.66 & 126.0 & 17.5 & 4.528 \\
\hline \multirow[t]{7}{*}{$\mathrm{H}$} & LORRAINE & 3 & 2.77 & 120.5 & 18.5 & 5.727 \\
\hline & ALSACE & 2 & 1.91 & 128.5 & 17.7 & 7.036 \\
\hline & FRANCHE-COMTÉ & 1 & 1.32 & 101.5 & 19.3 & 5.358 \\
\hline & PAYS DE LA LOIRE & 2 & 3.67 & 94.5 & 19.9 & 4.447 \\
\hline & BRETAGNE & 2 & 3.32 & 110.5 & 21.9 & 5.491 \\
\hline & POITOU-CHARENTES & 1 & 1.88 & 90.0 & 21.4 & 7.608 \\
\hline & AQUITAINE & 3 & 3.30 & 91.5 & 23.8 & 8.06 \\
\hline $\mathrm{S}$ & MIDI-PYRÉNÉES & 3 & 2.86 & 84.5 & 24.2 & 6.152 \\
\hline $\mathrm{O}$ & LIMOUSIN & 1 & 0.83 & 99.0 & 28.4 & 6.626 \\
\hline $\mathrm{U}$ & RHÔNES-ALPES & 9 & 6.45 & 92.5 & 18.7 & 7.107 \\
\hline $\mathrm{T}$ & AUVERGNE & 1 & 1.55 & 104.0 & 23.7 & 5.016 \\
\hline \multirow[t]{3}{*}{$\mathrm{H}$} & LANGUEDOC-ROUSSILLON & 4 & 2.50 & 92.5 & 24.6 & 7.018 \\
\hline & $\begin{array}{c}\text { PROVENCE - } \\
\text { ALPES-CÔTE D'AZUR }\end{array}$ & 9 & 5.07 & 83.0 & 23.2 & 6.655 \\
\hline & FRANCE & 68 & 67.57 & 100.0 & 19.9 & 5.96 \\
\hline
\end{tabular}

${ }^{\mathrm{a}} \mathrm{ON}=$ Observed numbers of cardiovascular units

${ }^{\mathbf{b}} \mathrm{EN}=$ Estimated numbers of cardiovascular units = population of each district divided by 850,000

${ }^{\mathbf{c}} \mathrm{SMR}=$ Standardized Mortality Ratio due to myocardial infarction per region (ICM9-CD 410 to 414 )

${ }^{\mathrm{d}} \mathrm{ECC}=$ Extracorporeal Circulation 
Table 2: Age structure of Nord-Pas-de-Calais and France (General census 1990).

\begin{tabular}{ccc}
\hline & France $\%$ & $\begin{array}{c}\text { NPDC } \\
\text { region } \%\end{array}$ \\
\hline 0-19 years & $25.3 \%$ & $28.0 \%$ \\
20-39 years & $27.8 \%$ & $28.8 \%$ \\
40-59 years & $25.7 \%$ & $24.5 \%$ \\
60-79 years & $17.2 \%$ & $15.8 \%$ \\
80 and over & $3.9 \%$ & $2.9 \%$ \\
Total population & $59,101,373$ & $3,965,058$ \\
\hline
\end{tabular}


Table 3: Open heart surgery inpatient recruitment in 1996 at Lille University Hospital's two units.

\begin{tabular}{cccc}
\hline $\begin{array}{c}\text { Inpatient recruitment for open } \\
\text { heart surgery }\end{array}$ & Unit 1 & Unit 2 & Total \\
\hline Coronary diseases & 396 & 270 & 666 \\
Valvular diseases & 286 & 194 & 480 \\
\hline
\end{tabular}


Table 4: Observed inpatient numbers and rates for coronary and valvular disease subgroups.

\begin{tabular}{|c|c|c|c|c|c|c|}
\hline \multirow[b]{2}{*}{$\mathrm{N}^{\circ}$} & \multirow[b]{2}{*}{ Sanitary sectors } & \multirow[b]{2}{*}{$\begin{array}{l}\text { Population } \\
\text { in } 1990\end{array}$} & \multicolumn{2}{|c|}{ Coronary diseases } & \multicolumn{2}{|c|}{ Valvular diseases } \\
\hline & & & $\begin{array}{l}\text { Observed } \\
\text { cases }\end{array}$ & $\begin{array}{c}\text { Observed } \\
\text { surgical } \\
\text { intervention } \\
\text { rates per } \\
10,000 \\
\end{array}$ & $\begin{array}{c}\text { Observed } \\
\text { cases }\end{array}$ & $\begin{array}{c}\text { Observed } \\
\text { surgical } \\
\text { intervention } \\
\text { rates per } \\
10,000 \\
\end{array}$ \\
\hline 1 & Dunkerque & 262,692 & 30 & 1.14 & 22 & 0.84 \\
\hline 2 & Calais/St Omer & 262,891 & 25 & 0.95 & 32 & 1.22 \\
\hline 3 & $\begin{array}{l}\text { Boulogne sur } \\
\text { mer/Montreuil }\end{array}$ & 265,925 & 29 & 1.09 & 17 & 0.64 \\
\hline 4 & Béthune & 267,899 & 49 & 1.83 & 49 & 1.83 \\
\hline 5 & Lens & 380,793 & 101 & 2.65 & 60 & 1.58 \\
\hline 6 & Douai & 254,210 & 50 & 1.97 & 36 & 1.42 \\
\hline 7 & Valenciennes & 375,536 & 76 & 2.02 & 54 & 1.44 \\
\hline 8 & Maubeuge & 218,196 & 43 & 1.97 & 34 & 1.56 \\
\hline 9 & Cambrai & 166,739 & 31 & 1.86 & 19 & 1.14 \\
\hline 10 & Arras & 232,387 & 46 & 1.98 & 33 & 1.42 \\
\hline \multirow[t]{2}{*}{11} & Lille & $1,277,790$ & 186 & 1.46 & 124 & 0.97 \\
\hline & Total & $3,965,058$ & 666 & 1.68 & 480 & 1.21 \\
\hline
\end{tabular}


Table 5: Simulation of variations in the Lille University Hospital's activity according to 9 scenarios.

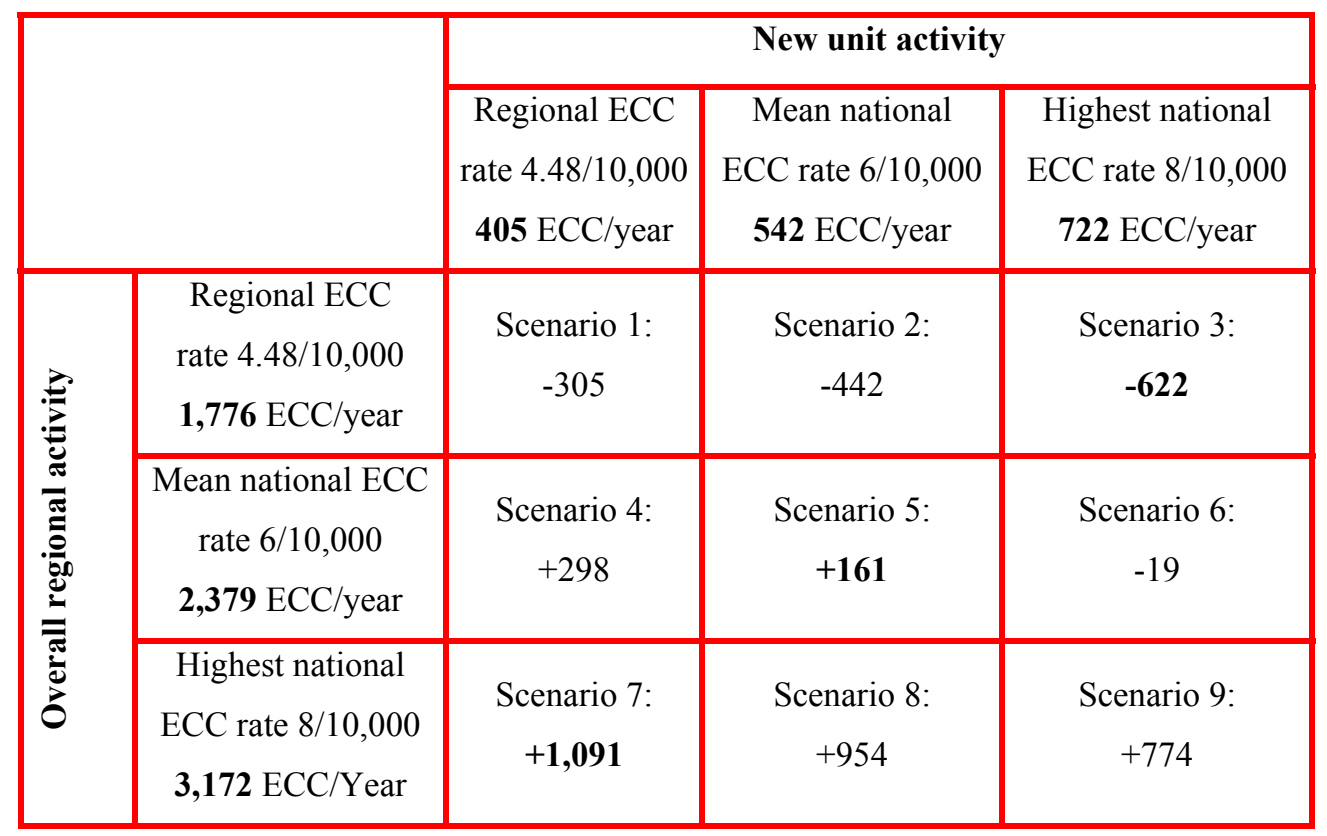


Figure 1:

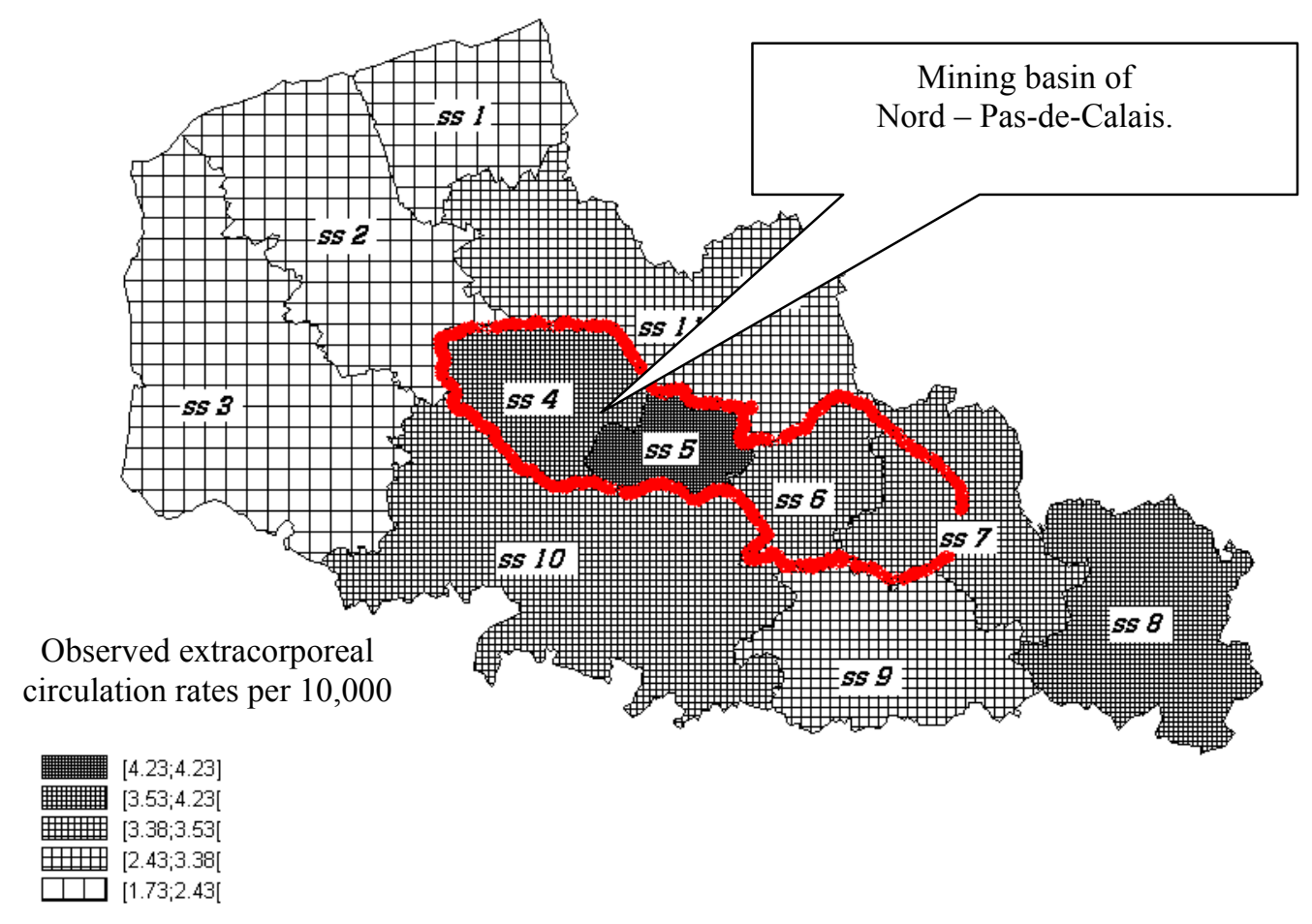




\section{LEGEND TO FIGURE}

Figure 1: Lille University Hospital's observed open heart surgical intervention rates (per 10,000 population) by sanitary sector. 